\title{
TIME-TEMPERATURE-STRESS DEPENDENCE OF BORON FIBER DEFORMATION
}

by James A。 DiCarlo

Lewis Research Center

Cleveland, Ohio 44135

TECHNICAL, PAPER to be presented at

Fourth Conference on Composite Materials Testing: and Design sponsored by the American

Society for Testing and Materials

Valley Forge, Pennsylvania, May 3-4, 1976 



\section{TIME-TEMP ERATURE-STRESS DEPENDENCE \\ OF BORON FIBER DEFORMATION}

J.A. DiCarlo ${ }^{1}$

Lewis Research Center

ABSTRACT

Flexural stress relaxation (FSR) and flexural internal friction (FIF) techniques were employed to measure the time-dependent deformation of boron fibers from -190 to $800^{\circ} \mathrm{C}$. The principal specimens were $203 \mu \mathrm{m}$ ( $8 \mathrm{mil}$ ) diameter fibers commercially produced by chemical vapor deposition (CVD) on a $13 \mu \mathrm{m}$ tungsten substrate. The observation of complete creep strain recovery with time and temperature indicated that CVD boron fibers deform flexurally as anelastic solids with no plastic component. The mechanical relaxation processes responsible for the anelasticity were found to be controlled by a continuous distribution of thermally activated relaxation times $\tau=\tau_{0} \exp (\mathrm{Q} / \mathrm{kT})$. Excellent fit of the FSR data with FIF data was obtainable across more than seven time decades by assuming that all processes have the same $\ln \tau_{0}(=-33.1)$ but are continuously and broadly distributed in energy $Q$. The incorporation of the derived distribution parameters into anelastic theory yielded simple analytical equations to describe the time-temperature-stress dependence of CVD boron fiber deformation at low strains. In order to extend the flexural results to high strain and to conditions of axially applied stress, an analysis of fiber axial deformation was made using data from the literature and from our own

\section{$\mathbf{1}_{\text {Solid State Physicist; } \text { Material Science Branch, Lewis Research }}$} Center, National Aeronautics and Space Administration, Cleveland, Ohio 44135 
fracture measurements. For the latter study etched fibers were employed to ensure core-initiated fracture. A model of a "composite" fiber with an anelastic sheath and elastic core was assumed in order to convert fracture stress versus time-temperature data to anelastic relations descriptive of axial deformation. These results in combination with literature data confirm the flexural result that up to at least $800^{\circ} \mathrm{C}$ all nonelastic axial behavior of CVD boron fibers can be explained solely by anelastic mechanisms. Diameter, core coating, etching, and manufacturing source appear to negligibly affect boron sheath anelasticity. With a simple empirical model to account for observed stress effects, final analytical equations and curves are presented to describe total axial deformation strain. These relations are further developed to demonstrate the significant effects of anelasticity on such fiber/composite properties as modulus, creep, creep recovery, stress relaxation, and damping capacity。 Finally, under the elastic-core/anelastic-sheath model, modern boron fibers on tungsten substrates are shown to have predictable fracture stresses for timetemperature conditions ranging from impact to long time stress rupture. Possible techniques for altering these stresses are discussed.

\section{INTRODUCTION}

In the design and analysis of metal matrix composites reinforced by chemically vapor-deposited (CVD) boron fibers, the deformation character of the fiber is generally assumed to be elastic. Support for the elastic approximation arises from observations of small fiber axial creep near the maximum use temperatures of aluminum and titanium matrix composites [1, 2]: This creep is usually accepted as predominantly plastic in origin. Recently, however, flexural studies have indicated only anelastic 
deformation in CVD boron fibers with no evidence of plasticity at composite use temperatures and above $[3,4]$.

Our objectives in this paper are twofold. First, we will demonstrate that up to at least $800^{\circ} \mathrm{C}\left(1412^{\circ} \mathrm{F}\right)$ all nonelastic behavior observed during the axial deformation of CVD boron fibers can be explained solely by anelastic mechanis ms. This will be accomplished by first deriving anelastic parameters and equations descriptive of our low strain flexural relaxation data. These anelastic relations combined with a simple empirical stress model will then be shown to describe well the time-temperaturestress dependence of axial deformation data taken from both published reports and our own fiber fracture experiments. Our second objective is to demonstrate that, although creep strains are small, boron fiber anelasticity can produce significant mechanical effects which would otherwise be neglected under the elastic approximation. This will be accomplished in the Discussion Section by considering the design implications of anelasticity for such fiber/composite properties as modulus, creep, creep recovery, stress relaxation, and damping capacity. In addition, the role of boron creep in the fracture of modern fibers vapor deposited on tungsten wire substrates will be considered. These particular fibers are suggested to have controllable and predictable time-temperature-dependent failure modes.

\section{ANELASTICITY}

The theory describing anelastic phenomena is discussed quite well els ewhere [5]. Our only purpose here is to introduce briefly those concepts and relations necessary for a practical understanding of boron deformation.

Upon application of a unidirectional stress $\sigma$ to an anelastic solid at 
time $t=0$ and temperature $T$, one obtains a total deformation strain

$$
\epsilon_{\mathrm{D}}(\mathrm{t}, \mathrm{T}, \sigma)=\epsilon_{\mathrm{e}}(\sigma, \mathrm{T})+\epsilon_{\mathrm{a}}(\mathrm{t}, \mathrm{T}, \sigma)
$$

Here $\epsilon_{\mathrm{e}}=\sigma_{\mathrm{u}}(\mathrm{T})=\sigma\left[\mathrm{E}_{\mathrm{u}}(\mathrm{T})\right]^{-1}$ is the time-independent elastic strain which depends on $T$ only through the unrelaxed compliance $J_{\mathfrak{u}}$ or Young's modulus $E_{u^{\circ}}$ The anelastic strain $\epsilon_{a}$ is zero at $t=0$, but develops with time, temperature, and stress. The three deformation properties which characterize $\epsilon_{\mathrm{a}}$ and distinguish it from plastic behavior are

I. Linearity: $\epsilon_{\mathrm{a}}$ is directly proportional to $\sigma$ 。

II. Equilibrium: After passage of sufficient time, $\epsilon_{\mathrm{a}}$ reaches or relaxes to a unique equilibrium value.

III. Recoverability: Upon removal of $\sigma$, the developed $\epsilon_{\mathfrak{a}}$ completely disappears at a rate which is time and temperature dependent.

From property I it is important to realize that an anelastic solid will creep at any stress level. This behavior can be considered to give rise to a time-temperature-dependent compliance

$$
J(t, T)=\epsilon_{D}(t, T, \sigma) / \sigma=J_{u}(T)[A(t, T)]
$$

where the stress-independent anelastic strain function $\mathrm{A}$ is defined here as

$$
\mathrm{A}(\mathrm{t}, \mathrm{T})=\left[\frac{\epsilon_{\mathrm{D}}}{\epsilon_{\mathrm{e}}}\right](\mathrm{t}, \mathrm{T})=1+\left[\frac{\epsilon_{\mathrm{a}}}{\epsilon_{\mathrm{e}}}\right](\mathrm{t}, \mathrm{T})
$$

It follows, therefore, that accurate values of $J_{u}(T)$ can only be obtained near times of $\mathrm{t}=0$. In addition, for a stress-relaxation experiment in which a constant strain $\epsilon$ is applied, property I implies that $\sigma(t, T, \epsilon)$ is linear with $\epsilon$. Thus, as with the compliance, anelasticity gives rise to a time-temperature-dependent modulus

$$
E(t, T)=E_{u}(T)[m(t, T)]
$$


The strain-independent modulus ratio $m$ defined here by Eq. (4) decreases with time from a value of unity at $t=0$. In general, $A(t) m(t) \leq 1$.

Phenomenologically anelasticity can be described as the stress-induced relaxation of some microstructural entity of type i from one internal position to another with a relaxation time $\tau_{\mathbf{i}}$. Continual motion is inhibited by the buildup of local elastic stresses which oppose the applied stress. Thus the resulting anelastic strain follows a time dependence

$$
\epsilon_{\mathrm{a}}^{\hat{1}}(\mathrm{t}, \mathrm{T}, 0)=\epsilon_{\mathrm{e}}(\mathrm{T}, \sigma) \Delta_{\dot{i}}\left[1-\exp \left(-\mathrm{t} / \tau_{\dot{1}}\right)\right]
$$

where the relaxation strength $\Delta_{i}$ is a measure of the number and extent of type i relaxations. Usually, because of internal variations, the relaxing entities are continuously distributed in relaxation time. One can account for this analytically by a continuous function $\chi(\ln \tau)$ which is defined through the total relaxation strength $\Delta$; i. e.

$$
\Delta=\int_{-\infty}^{\infty} x(\ln \tau) \mathrm{d}(\ln \tau)
$$

If the $\tau$ distribution is broad (as in CVD boron), the bracketed term in Eq。 (5) can be approximated by unity for $\tau_{i}<t$ and zero for $\tau_{i}>t$. Thus for the broad distribution approximation (hereafter BDA), Eqs. (3), (5), and (6) yield

$$
A(t, T)=1+\int_{-\infty}^{\ln t} x(\ln \tau) d(\ln \tau)
$$

thereby permitting determination of total deformation $\epsilon_{\mathrm{D}}$ from Eq. (2) and a knowledge of $\chi(\ln \tau)$. Temperature variation appears in Eq. (7) primarily because the relaxation processes in boron and many other systems are controlled by thermally activated relaxation times; i. e.,

$$
\tau=\tau_{\mathrm{O}} \exp (\mathrm{Q} / \mathrm{kT})
$$


The parameter $Q$ is the height of the energy barrier for relaxation, $\tau_{0}=\left(2 \pi f_{0}\right)^{-1}$ where $f_{0}$ is the number of times per second the relaxing entity attempts to cross the barrier, and $\mathrm{k}$ is Boltzmann's constant. Clearly distributions in $\tau$ can arise from distributions in $\tau_{0}$ or in $\mathrm{Q}$, or in both parameters.

\section{FLEXURAL DEFORMATION}

The unusually large anelasticity of CVD boron fibers is demonstrated in our recent measurements of flexural stress relaxation (FSR) and flexural internal friction (FIF) [4]. The principal specimens were $203 \mu \mathrm{m}$ ( 8 mil) diameter fibers commercially supplied by Avco Systems Division. These fibers were produced in a single stage reactor by the hydrogen reduction of boron trichloride on a $13 \mu \mathrm{m}(0.5 \mathrm{mil})$ tungsten wire substrate held near $1300^{\circ} \mathrm{C}\left(2372^{\circ} \mathrm{F}\right)$. The FSR and FIF data of Ref. 4 will now be reexamined for the purpose of deriving the fiber anelastic strain function $\mathrm{A}(\mathrm{t}, \mathrm{T})$.

For the FSR data shown in Fig. 1, the stress or modulus ratio was determined from

$$
\mathrm{m}\left(\mathrm{t}, \mathrm{T}, \epsilon_{\mathrm{o}}\right)=\frac{\sigma\left(\mathrm{t}, \mathrm{T}, \epsilon_{\mathrm{o}}\right)}{\sigma\left(0, \mathrm{~T}, \epsilon_{\mathrm{o}}\right)}=\frac{\epsilon_{\mathrm{e}}\left(\mathrm{t}, \mathrm{T}, \epsilon_{\mathrm{o}}\right)}{\epsilon_{\mathrm{o}}}=1-\frac{\epsilon_{\mathrm{a}}\left(\mathrm{t}, \mathrm{T}, \epsilon_{\mathrm{o}}\right)}{\epsilon_{\mathrm{o}}}
$$

As indicated in Fig. 1, values of the ratio $\epsilon_{\mathrm{a}} / \epsilon_{\mathrm{O}}$ were measured optically by the ratio $\mathrm{x}_{\mathrm{a}} / \mathrm{x}_{\mathrm{o}}$ for cantilevered specimens held at low strain by end displacement $X_{o}$ and by the ratio $R_{o} / R_{a}$ for specimens held at high strain by constant radius of curvature $R_{0}$. The anelastic deformations $\mathrm{X}_{\mathrm{a}}$ and $\mathrm{R}_{\mathrm{a}}$ were produced by heat treating the fibers in vacuum at temperature $T$ for a time $t$ of 1.0 hours, quenching, and removing the applied deformations $x_{o}$ and $R_{o}$, respectively. The conclusion that the 
FSR data were entirely due to anelastic sources was based on the observation that all flexural deformations $\mathrm{X}_{\mathrm{a}}$ and $\mathrm{R}_{\mathrm{a}}$ could be completely removed by reheating the fibers under zero applied deformation (property of complete recoverability). In addition, the low strain $\mathrm{m}$ data of curve a was independent of end displacement and diameters between 102 and $203 \mu \mathrm{m}$ ( 4 and 8 mil). As will be discussed, the increased stress relaxation at low temperatures for curve $b$ was presumably caused by a stress-induced activation of anelastic processes which were inhibited from operating at low strains by some unknown microstructural locking mechanism.

The extended temperature range of the FSR indicated that the deformation strains were produced by thermally activated relaxation processes broadly distributed in controlling parameters. To determine whether this distribution was in $\tau_{0}, Q$, or in both, the low strain FSR data were supplemented with low strain $\left(\sim 10^{-5}\right)$ FIF data from -190 to $800^{\circ} \mathrm{C}(-310$ to $\left.1472^{\circ} \mathrm{F}\right)$. The log decrement $\delta$ was measured during free decay of cantilevered fibers vibrating at their fundamental and first overtone resonant modes [6]. Operating at resonance allows one also to determine the temperature and frequency dependence of the fiber's Young's modulus. At $22^{\circ} \mathrm{C}\left(72^{\circ} \mathrm{F}\right)$ and frequencies from $10^{2}$ to $10^{4} \mathrm{~Hz}$, all modulus data fell within $393 \pm 14 \mathrm{GN} / \mathrm{m}^{2}(57 \pm 2 \mathrm{Msi})$. Figure 2 presents typical high temperature FIF data at two modes of the same specimen. The best fit by far to both the FIF and FSR data was obtained by assuming all responsible relaxation processes had the same $\tau_{0}$ but were continuously and broadly distributed in $Q$. In this situation it is convenient to introduce the enery distribution $\mathrm{B}(\mathrm{q}) \mathrm{dq}$ which is defined through the total relaxation strength 


$$
\Delta=\int_{0}^{\infty} \mathrm{B}(\mathrm{q}) \mathrm{dq}=\int_{\ln \tau_{0}}^{\infty} x(\ln \tau) \mathrm{d}(\ln \tau)
$$

Here $q \equiv 10^{-3} \mathrm{Q} / \mathrm{k}$, and the lower $-\infty$ limit on the $x$ integral has been replaced by the $\ln$ of the shortest relaxation time $\tau_{0^{\circ}}$ Employing the broad distribution approximation (BDA) plus Eqs。(7), (8), and (10), one derives the anelastic strain function

$$
A(t, T)=A(q)=1+\int_{0}^{q} B(q) d q
$$

where now the energy parameter

$$
q=\left(\ln t-\ln : \tau_{0}^{j}\right) T\left(10^{-3}\right)
$$

contains both the time $(\mathrm{sec})$ and temperature $\left({ }^{\circ} \mathrm{K}\right)$ dependence.

The best fit situation was determined by adjusting $l_{1} \tau_{0}$ in the $q$ parameter until the A's calculated from all sets of low strain flexural data agreed. For the FIF data BDA allows one to convert frequency $f$ to time $t=(2 \pi f)^{-1}$ and to calculate $A$ from

$$
A^{F I F}(q)=\exp \left[\int_{0}^{q} \frac{2\left(10^{3}\right) \delta(t, T)}{\pi^{2} T} d q\right\}_{t=(2 \pi f)^{-1}}
$$

For $\ln \tau_{0}=-33.1$ all FIF data yielded the $A(q)$ solid line of Fig. 3. Because internal friction was still finite below $-190^{\circ} \mathrm{C}\left(-310^{\circ} \mathrm{F}\right)$, an extrapolation of the $\delta$ data to $0^{\mathrm{O}} \mathrm{K}$ was necessary for use of Eq. 13. Although the relaxation processes responsible for $\delta$ below $q=10$ make a negligible contribution to $\mathrm{A}^{\mathrm{FIF}}$, their existence implies that some anelastic deformation occurs in CVD boron fibers even at room temperature. Thus the assumption inherent in the FSR measurements that $\epsilon_{\mathrm{a}}$ after quenching was stable at $22^{\circ} \mathrm{C}\left(72^{\mathrm{O}} \mathrm{F}\right)$ was not strictly correct. To 
account for this effect in calculating $A$ for the low strain FSR data, the $\mathrm{BDA}$ result $\mathrm{Am}=1$ was employed so that

$$
\mathrm{A}^{\mathrm{FSR}}(\mathrm{q})=\mathrm{A}\left(\mathrm{t}_{1}, \mathrm{~T}\right) / \mathrm{m}(\mathrm{t}, \mathrm{T})=\mathrm{A}\left(\mathrm{q}_{1}\right) / \mathrm{m}(\mathrm{q})
$$

Here $A\left(q_{1}\right)$ is a measure of the anelastic strain lost between $\epsilon_{0}$ removal at $\mathrm{t}=0$ and the FSR measurement at $\mathrm{t}_{1}$ and $\mathrm{T}=295^{\circ} \mathrm{K}$. For $\mathrm{q}_{1} \cong 12$, $\mathrm{A}^{\mathrm{FIF}}\left(\mathrm{q}_{1}\right)=1.025$, and the low strain $\mathrm{m}$ data of Fig. 1, one obtains the open circle FSR results of Fig. 3. In the $q$ determination, $\ln \tau_{0}$ was taken as -33.1 and $\ln t$ was replaced by $\ln t+0.6$ as discussed in Ref. 7 to account for both the broadness and quasistatic nature of the FSR.

The excellent agreement between $A^{F S R}$ and $A^{F I F}$ below $q=25$ clearly supports the model in which relaxation processes are broadly distributed in $\mathrm{Q}$ but have essentially the same ln $\pi_{0}$. The $\mathrm{A}$ agreement is especially dramatic when one considers that some of the data differ in time by almost eight orders of magnitude. The deviation in the $A$ curves above $q=25$ has previously been interpreted [4] as evidence of another set of relaxation processes (Type $\mathrm{Ib}$ ) still distributed in $\mathrm{Q}$ but with $\ln \tau_{0} \cong-26$. However, as will be developed shortly, it appears that a more appropriate explanation for the $\mathrm{A}$ difference at high $\mathrm{q}$ is the difference in applied strain between the FSR data $\left(\bar{\epsilon} \cong 10^{-3}\right)$ and the FIF $\operatorname{data}\left(\bar{\epsilon} \cong 10^{-5}\right)$.

Although one could now determine the low stress/low q total flexural deformation of CVD boron fibers by Eq. (2) and the $\mathrm{A}(\mathrm{q})$ of $\mathrm{Fig}$. 3 , it was clear from curve $\underline{b}$ of Fig. 1 that a significant change in $A(q)$ occurred at high stress levels. Because investigation of this stress effect was complicated by the existence of stress gradients in flexed fibers, we undertook a study of the axial deformation of CVD boron fibers 
both by our own fracture experiments and by an anelastic analysis of axial data in the literature. It was our hope to understand not only the stress dependence (at least empirically) but also the extent to which anelastic processes contribute to total axial deformation. Included in the axial data, for example, would be the relaxation effects of the core region which was subjected to negligible stress during the flexural measurements.

\section{AXIAL DEFORMATION}

Approach. - A new indirect approach was developed to determine the time-temperature-stress dependence of boron fiber axial deformation. This approach is based on the recent tensile results of Smith [8] who measured at $22^{\circ} \mathrm{C}\left(72^{\circ} \mathrm{F}\right)$ the ultimate tensile strength (UTS) of $203 \mu \mathrm{m}$ ( $8 \mathrm{mil}$ ) fibers from the same commercial run that provided the previous flexural specimens. Smith found that after etching a few $\mu \mathrm{m}$ off the surface of as-received fibers, essentially all cases of fracture could be explained by crack initiation within the region of the tungsten boride core, Apparently after surface removal, those flaws that remained in the boron sheath could not initiate fracture at the level of the core flaw strength. Smith observed that the UTS had a coefficient of variability of less than five percent and increased monotonically as etched fiber diameter decreased, reaching values as high as $5.7 \mathrm{GN} / \mathrm{m}^{2}(820 \mathrm{ksi})$ near $102 \mu \mathrm{m}(4 \mathrm{mil})$.

The above UTS results of Smith suggest that the etched fiber fractures whenever its total axial deformation $\epsilon_{\mathrm{D}}(\mathrm{t}, \mathrm{T}, \sigma)$ becomes equal to the core fracture strain $\epsilon_{\mathrm{F}^{\circ}}^{\mathrm{C}}$. Assuming the core region behaves as a brittle elastic material ( $c f$, appendix I), our approach to axial deformation was simply to measure the fiber fracture stress $\sigma_{F}(t, T)$ required for the 
boron sheath to attain $\epsilon_{\mathrm{F}}^{\mathrm{C}}$. Neglecting the stress contribution of the small $17 \mu \mathrm{m}(0.67 \mathrm{mil})$ core and assuming only q-type anelastic behavior, one can then calculate the axial strain function $\mathrm{A}(\mathrm{q})$ from $\mathrm{Eq}$. (2):

$$
A(q)=\frac{E_{u}(T) \epsilon_{F}^{C}(d)}{\sigma_{F}(q, d)}=\left[\frac{E_{u}(T)}{E_{u}\left(0^{\circ} K\right)}\right] \frac{\sigma_{F}(o, d)}{\sigma_{F}(q, d)}
$$

where $d$ is the diameter of the etched fiber. Smith's observation of a low coefficient of variability in $\sigma_{F}$ suggested that sufficiently accurate $\sigma_{F}(q, d)$ data could be obtained. Possible sources of temperature variation in $\epsilon_{\mathrm{F}}^{\mathrm{C}}(\mathrm{d})$ or $\sigma_{\mathrm{F}}(\mathrm{o}, \mathrm{d})$ are discussed in appendix I. Finally, because modulus is directly proportional to the square of the resonant frequency $f$, the unrelaxed modulus ratio in Eq. (15) was determined from $f(T)$ as measured in FIF (cf. Fig。2); i.e.,

$$
\frac{E_{u}(T)}{E_{u}(o)}=\left[\frac{f(T)}{f(o)}\right]^{2} \frac{A^{F I F}(f, T)}{1+\lambda(T)}
$$

The slight effect of thermal expansion on $f(T)$ is contained in the parameter $\lambda(T)$ (cf。 appendix II). The calculated $\mathrm{E}_{\mathrm{u}}(\mathrm{T})$ is plotted in Fig, 4 in terms of the ratio $\mathrm{E}_{\mathrm{u}}(\mathrm{T}) / \mathrm{E}_{\mathrm{u}}\left(295^{\circ} \mathrm{K}\right)$. Etching was found to have no effect on $E_{u}(T)$.

Procedure and results. - Etched specimens for the fracture measurements were prepared in the following manner. As-received $203 \mu \mathrm{m}$ (8 mil) fibers of length $(2 l-2.5) \mathrm{cm}$ were inserted vertically into a $l(>10) \mathrm{cm}$ deep etchant solution of two parts nitric acid and one part water at $100^{\circ} \mathrm{C}$. Upon removal of $30 \mu \mathrm{m}$ (1.2 mils) off the diameter in about five minutes, the fiber was reversed in the solution until $30 \mu \mathrm{m}$ was etched off the diameter of the other end. After a cleaning in distilled water followed by methanol, the final dimensions of the etched fiber consisted of a $2.5 \mathrm{~cm}$ 
(1.0 in.) long center section with $143 \mu \mathrm{m}(5.6 \mathrm{mil})$ diameter and $(l-2.5)$ $\mathrm{cm}$ long end sections with $173 \mu \mathrm{m}(6.8$ mil) diameter. This geometry insured fracture data from the $2.5 \mathrm{~cm}(1.0 \mathrm{in}$. $)$ center gage section.

For calculation of $\mathrm{A}(\mathrm{q})$, it was necessary to determine $\sigma_{F}(o, d)$, the fracture stress at $d=143 \mu \mathrm{m}$ and $q$ or $T=0$. Because test temperatures at absolute zero were not possible, $\sigma_{F}$ was measured near $-195^{\circ} \mathrm{C}$ $\left(-319^{\circ} \mathrm{F}\right)$ by surrounding the gage length of the etched fibers with liquid nitrogen and pulling the specimen to fracture in a standard tensile test. For such a test, the BDA allows one to calculate $q$ simply from the time of stress application. For $q=3,0$, the average UTS \pm standard deviation of 10 specimens was $5.54 \pm 0.30 \mathrm{GN} / \mathrm{m}^{2}(804 \pm 43 \mathrm{ksi})$. When this result is compared to Smith's $q=11.8$ values of $5.03 \pm 0.16 \mathrm{GN} / \mathrm{m}^{2}(730 \pm 23 \mathrm{ksi})$, the significant effect of boron sheath creep as low as room temperature becomes obvious. Assuming at low $q$ a direct proportionality between $A$ and $q$, one calculates an extrapolated average $\bar{\sigma}_{F}(o, d)$ of $5.75 \mathrm{GN} / \mathrm{m}^{2}$ (834 ksi). As discussed in appendix $I_{\text {, this }} \bar{\sigma}_{F}$ value should increase slightly as test temperatures exceed the etch temperature of $100^{\circ} \mathrm{C}\left(212^{\circ} \mathrm{F}\right)$.

For the high temperature fracture tests, the etched fibers were inserted into a vertical furnace heated by a $7.6 \mathrm{~cm}(3$ in. $)$ long tantalum element with a $1.3 \mathrm{~cm}(0.5 \mathrm{n}$ 。 $)$ bore. After the fiber ends were mechanical clamped with the gage section centered in the furnace, the lower fiber end was loaded to a stress level $\sigma_{F}$ by the addition of a known weight. The furnace chamber including the load was closed and evacuated to less than $3 \times 10^{-6} \mathrm{~mm} \mathrm{Hg}$. Heat was then applied to provide a specimen warmup rate of about $1.0^{\circ} \mathrm{C}$ per sec. Temperature was measured with a chromel-alumel ther mocouple located $\sim 2 \mathrm{~mm}$ from specimen center. 
Thermal gradients were less than $10^{\circ} \mathrm{C}$ along the gage length. Furnace shutdown was automatic upon fiber fracture. Diameters of the fractured ends were measured optically in two perpendicular directions with an accuracy of $0.5 \mu \mathrm{m}(0.02$ mils $)$.

Fracture stress data for a few fibers etched to a $143 \mu \mathrm{m}$ diameter are shown in Fig. 5 as a function of fracture temperature $T_{F}$. Optical microscopy indicated that in all cases fracture was initiated by flaws within the core region. To determine $q$ for each high temperature data point, Eq. (12) was maximized under the condition that both $t$ and $T$ were varying during warmup rate $\gamma$. It can be shown that as long as $1<\mathrm{T}_{\mathrm{F}} / \gamma<10^{6} \mathrm{sec}$, the proper time and temperature for the $\mathrm{q}$ parameter are $0.01 \mathrm{~T}_{\mathrm{F}}$ and $\mathrm{T}_{\mathrm{F}}$, respectively. Thus the closed circle points of Fig. 5 can be considered as stress-rupture data where the failure life is about $10 \mathrm{sec}$.

With consideration of possible temperature variation in $\sigma_{F}(0, d)$ as

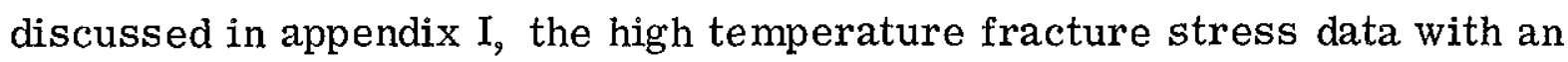
assumed five percent coefficient of variability were inserted into Eq. (15) to determine the axial anelastic strain function $A(q)$. The results are shown as curve $\mathrm{A}_{\mathrm{H}}$ in Fig。6. It is assumed a priori that the relaxation distribution parameters determined for $q<25$ apply for all data indicated. Also included in this plot is the low strain $\mathrm{A}_{\mathrm{L}}$ function from Fig. 3. Rather than distinguishing stress modes, the subscripts $H$ (high) and $\mathrm{L}_{\mathrm{s}}(\mathrm{low})$ indicate the qualitative stress level at which each $\mathrm{A}$ data set was taken.

To evaluate the validity of our approach, the anelastic $A(q)$ equations were applied to axial deformation data within the literature. Because 
anelastic creep occurs at all stress levels, accurate A derivations require total deformation versus time curves rather than approximate creep strain curves. This requirement is met in the $102 \mu \mathrm{m}$ (4 mil) fiber data of Rose and Stokes at $538^{\circ} \mathrm{C}\left(1000^{\circ} \mathrm{F}\right)$ [9]. When their time-dependent results at three stress levels are converted to $A(q)$ by $E q$. (2), the short solid lines near $q=35$ in Fig, 6 are obtained. Regarding measurements similar to our own fracture tests, Veltri and Galasso [10] have determined the UTS ratio $\sigma_{\mathrm{F}}(\mathrm{T}) / \sigma_{\mathrm{F}}\left(295^{\circ} \mathrm{K}\right)$ for $102 \mu \mathrm{m}(4 \mathrm{mil})$ boron and silicon carbide-coated boron fibers. Assuming a temperature-independent fracture strain, a few second tensile test, and $\mathrm{A}\left(295^{\circ} \mathrm{K}\right)=1.15$, one can average their UTS ratios at each test temperature (except where surface contamination is obvious) and convert the data to $\mathrm{A}(\mathrm{q})$ by $\mathrm{Eq}$. (15). The calculated points and their variation are shown by the cross data in Fig. 6. It is seen that both the high stress creep and UTS axial data yield $A(q)$ values in good agreement with $\mathrm{A}_{\mathrm{H}}$ despite a variation in stress from 1.4 to $5.5 \mathrm{GN} / \mathrm{m}^{2}$ (200 to $800 \mathrm{ksi})$. This stress independence of $\mathrm{A}_{\mathrm{H}}$ indicates a linear relationship between strain and stress, thereby implying the validity of our original assumption of complete anelasticity in boron fiber axial deformation. In addition, the equivalence of the various sets of data suggests that above $\sim 1.7 \mathrm{GN} / \mathrm{m}^{2}$ (250 ksi) the axial $\mathrm{A}_{\mathrm{H}}$ is independent of diameter, manufacturing source, fiber coating, and etching.

Regarding axial deformation at low stress, Ericksen [11] recently found that the empirical relation

$$
\epsilon_{\mathrm{D}}(\mathrm{t})=\mathrm{C}(\sigma)+\alpha(\sigma) \log \mathrm{t}
$$

adequately described the total anelastic deformation of $102 \mu \mathrm{m}$ (4 mil) silicon carbide-coated boron fibers at $27^{\circ} \mathrm{C}\left(81^{\circ} \mathrm{F}\right)$ and $\mathrm{t}(\mathrm{h})$ from 0.01 
100. From the anelastic relations in Eqs. (3), (11), and (12), it follows that at constant $\mathrm{T}$

$$
\alpha(q, \sigma)=2.3\left(10^{-3}\right) \epsilon_{\mathrm{e}} \mathrm{TB}(\mathrm{q}, \sigma)
$$

Thus Ericksen's $\alpha$ parameter can be employed to determine the stress dependence of $B(q)$, the number of relaxation processes at $q$. For example, taking $\mathrm{q}_{\mathrm{O}}=12.6$ for one hour creep at $300^{\circ} \mathrm{K}$, one calculates the $\mathrm{B}\left(\mathrm{q}_{\mathrm{O}}\right)$ versus $\sigma$ plot of $\mathrm{Fig}$. 7. The closed circles are from Ericksen's fiber data whereas the squares are derived from his B/Al composite data assuming no matrix creep. Also included in Fig. 7 are the $\mathrm{B}\left(\mathrm{q}_{\mathrm{O}}\right)$ from our own low strain FIF and FSR data (open circles). Comparison of Fig. 7 with the low $q$ behavior of Fig. 6 indicates that the $B(q)$ responsible for $A_{L}$ is small at low stress. However, as stress exceeds some critical "breakaway" stress $\sigma^{*}$ of about $1.0 \mathrm{GN} / \mathrm{m}^{2}$ (150 ksi), B begins to rise rapidly, eventually saturating to produce the stress-independent $A_{H}$. The maximum $A\left(q_{O}\right)$ corresponding to Ericksen's data is plotted in Fig. 6 under the low $q$ assumption of a direct proportionality between $A$ and $q\left(i, e_{\circ}, B\right.$ independent of $q$ ).

It is of interest to apply this concept of a breakaway stress $\sigma^{*}$ to the Fig. 1 FSR data. For example, since the surface stress for curve $\underline{b}$ was greater than $2.2 \mathrm{GN} / \mathrm{m}^{2}(320 \mathrm{ksi})$, the maximum number of relaxation processes should have been operating so that at low $q$ the function $A_{H}$ is appropriate. Applying the Eq. (14) correction $A_{H}\left(q_{1}\right)=1.15$ to the high strain FSR data, one obtains the Fig. 6 curve labeled $A_{B}$ (open squares). Although agreement at low $q$ was forced by the $A_{H}\left(q_{1}\right)$ correction, the equivalence above $q=30$ between $A_{H}$ and $A_{B}$ is a significant result with many fundamental implications. First, it is another 
result suggesting that boron fiber axial deformation is completely anelastic. Second, the core region which was not stressed during flexure appears to contribute negligibly to axial deformation. Third, as also indicated in Fig。7, fiber deformation is essentially independent of the mode of stress application. Furthermore, if the same $A_{H}\left(q_{1}\right)$ correction is applied to the low strain FSR data above $q=30$, the calculated $A$ points in Fig。6 (open circles) are also in agreement with $A_{H}$ and $A_{B^{\circ}}$ This result suggests that the stress dependence of boron fiber anelasticity disappears near $q=35$. In terms of the breakaway stress model, one would conclude that $\sigma^{*}$ tends to zero above $q=35$. The Fig, 3 results further suggest that $\sigma^{*}$ is large up to $q=20$ but then starts to diminish, resulting in the strain-dependent deviation near $q=25$. One can incorporate these concepts into the approximate $q$ dependence for $\sigma^{*}$ shown schematically in the Fig。 6 insert。

On the practical side, a stress model which incorporates an abrupt transition from $A_{L}$ to $A_{H}$ at a certain stress level $\sigma^{*}$ is certainly a crude approximation, especially when one considers the residual stress pattern in CVD boron fibers [12]。 Nevertheless, the Fig. 7 results do indicate that such a model can serve as a first approximation for deciding which A function is operating under certain stress conditions. Ericksen's data and our own FSR data suggest a $\sigma_{\max }^{*}$ value somewhere near $1.0 \mathrm{GN} / \mathrm{m}^{2}(150 \mathrm{ksi})$ for $\mathrm{q}<20$. As temperature or $\mathrm{q}$ is raised, $\sigma^{*}$ should diminish somewhat in the manner indicated in the Fig。6 insert.

On the basic side, the above stress behavior suggests a microstructure model in which the application of high stress or high temperature loosens low q relaxation processes from internal locks so that they can 
operate and be observed. Firle in his internal friction study of $102 \mu \mathrm{m}$ (4 mil) fibers [13] came to a similar conclusion by suggesting a model of stress-induced dislocation breakaway. More recent work, however, has found no evidence of dislocations in CVD boron fibers [14]. Therefore, in keeping with our model previously developed [4], we suggest at the present time that the relaxing entities are boron icosohedron and the internal locks are unknown atomic imperfections quenched in after deposition. The dropoff of $\sigma^{*}$ with $q$ would then indicate some form of thermally assisted breakaway, perhaps caused by thermally induced mobility of the internal locks.

\section{DISCUSSION}

Although many basic microstructural implications can be drawn from the previous results [4], our only purpose here is to discuss briefly some important practical effects of anelasticity on the mechanical properties of CVD boron fibers and their composites.

Summarizing the results of the anelastic approach, one can completely describe the time-temperature-stress dependence of boron fiber axial deformation by the simple relation

$$
\epsilon_{D}(t, T, \sigma)=\frac{\sigma}{E_{u}(T)} A_{\sigma}(q)
$$

where

$$
\mathrm{q}=(\ln \mathrm{t}+\mathrm{C}) \mathrm{T}\left(10^{-3}\right)
$$

and

$$
\begin{aligned}
& A_{\sigma}=A_{L_{s}}(q), \quad \sigma<\sigma^{*}(q) \\
& A_{\sigma}=A_{H}(q), \quad \sigma>\sigma^{*}(q) .
\end{aligned}
$$

The $\mathrm{A}_{\mathrm{L}}, \mathrm{A}_{\mathrm{H}}$ and $\sigma^{*}$ are shown as functions of $\mathrm{q}$ in Fig. 6. The value 
of $\sigma^{*}{ }_{\max }$ is estimated to be about $1.0 \mathrm{GN} / \mathrm{m}^{2}(150 \mathrm{ksi})$. For quasistatic tests such as tensile, creep, and stress-relaxation, $t$ (sec) is the time of stress (strain) application and $\mathrm{C}=33.7$. For dynamic measurements at frequency $f, \sigma$ is the stress amplitude, $t=(2 \pi f)^{-1}$, and $C=33.1 . E_{u}(T)$ can be derived from Fig。 4 with a $\mathrm{E}_{\mathrm{u}}\left(295^{\circ} \mathrm{K}\right)$ value of $390 \mathrm{GN} / \mathrm{m}^{2}(57 \mathrm{Msi})$. For flexural tests, $A_{H}$ is replaced by $A_{B}$ of Fig. 6, and $\epsilon_{D}$ and $\sigma$ can be taken as the surface strain and stress, respectively.

With this analytical base, let us now consider the anelastic effects on some important fiber properties.

Modulus. - The anelastic fact that the total deformation strain is directly proportional to $\sigma$ leads to the significant practical result that

$$
\mathrm{E}(\mathrm{t}, \mathrm{T})=\sigma / \epsilon_{\mathrm{D}}(\mathrm{q})=\mathrm{E}_{\mathrm{u}}(\mathrm{T}) / \mathrm{A}_{\sigma}(\mathrm{q})
$$

Thus for Young's modulus measurement, the length of time during stress application can be critical. For example, in the low stress regime near room temperature, $A_{\sigma}=A_{L} \cong 1$ so that one can effectively measure $E_{u}$ from a stress-strain curve. However, at high stress or high temperature, $A_{\sigma}(q)>1$ so that stress-strain slopes gradually decrease during the time of test, thereby yielding an average modulus less than $E_{u}(T)$. Reported data which shows the $\mathrm{E}$ for boron decreasing rapidly with temperature and time $[15,16]$ are clear evidence of the anelastic effect.

This modulus behavior may become quite significant for fibers subjected to dynamic stress conditions at high temperature. For example, for low stress amplitude at $482^{\circ} \mathrm{C}\left(900^{\circ} \mathrm{F}\right)$ and $\mathrm{f}=10^{3} \mathrm{~Hz}$, published tensile test modulus data [15] yields $\mathrm{E}=240 \mathrm{GN} / \mathrm{m}^{2}$ (35 Msi), whereas the dynamic modulus using the above analysis is $350 \mathrm{GN} / \mathrm{m}^{2}$ (51 Msi). Increasing the frequency, of course, lowers the stress application time 
and raises the effective modulus toward $E_{u}(T)=370 \mathrm{GN} / \mathrm{m}^{2}$ (54 Msi).

Creep. - Because anelastic solids creep at all stress levels, it is difficult in a fiber creep test to separate the elastic strain from the timedependent anelastic strain without quenching to lower temperature and removing the stress. Therefore, in discussing creep it is more appropriate to consider the total deformation as given by $\mathrm{Eq}$. (17)。 Because of the $\ln t$ dependence in the $q$ parameter, $\epsilon_{D}$ at a given temperature will increase rapidly at short time and then level off somewhat as time progresses. Although it may be convenient to label this behavior as primary and secondary creep, due to a difference in mechanisms one should not equate it with similar creep behavior observed in metals.

Regarding creep rate, differentiation of $\mathrm{Eq}$. (17) yields

$$
\stackrel{\circ}{\epsilon}_{\mathrm{D}}(\mathrm{t}, \mathrm{T}, \sigma)=\frac{\sigma \mathrm{T}\left(10^{-3}\right)}{\mathrm{E}_{\mathrm{u}}(\mathrm{T}) \mathrm{t}}\left[\frac{\mathrm{dA}_{\sigma}}{\mathrm{d}_{\mathrm{q}}}\right]
$$

Thus in certain $q$ regions where $A$ is fairly constant (cf. Fig. 6), the ${ }^{i}$ secondary'i creep rate will vary inversely with time, until q values are reached where $\mathrm{A}$ increases again. Fundamentally it should be pointed out that macroscopic equilibrium or exhaustion of the anelastic processes is not observed in boron fibers because these processes are continuously distributed in energy or $q$. That is, when one process reaches microscopic equilibrium, another one at higher energy is activated so that creep strain saturation is never reached (at least to $q \cong 45$ ).

Finally, in those situations where different stresses $\sigma_{\mathbf{i}}$ are applied to a boron fiber at different times $t_{i}$, the Boltzmann superposition principle allows one to determine $\epsilon_{\mathrm{D}}(\mathrm{t})$ by summing the deformations from each stress as if each were acting alone $[5] ;$ i.e., 


$$
\epsilon_{D}(t, T)=\left[E_{u}(T)\right]^{-1} \sum \sigma_{i} A_{i}\left(t_{i}-t, T\right)
$$

For continuous stress application, the summation is replaced by an inte-

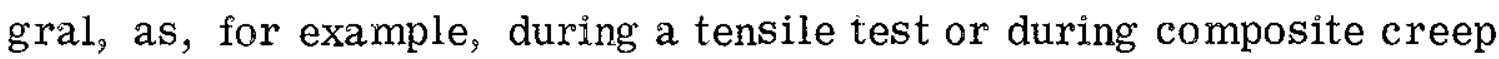
where load transfer to the fibers occurs during matrix stress relaxation. For these situations, because of the $\ln t$ dependence one introduces negligible error by employing Eq. (17) and assuming $t$ is the time from zero to maximum stress $\sigma$ 。

Creep recovery. - When the stress is removed from a solid which has crept anelastically, the creep strain gradually disappears with time and temperature. This behavior called the elastic aftereffect or creep recovery can be analytically described by use of the superposition principle. For example, if creep occurred during application of stress $\sigma_{0}$ for time $t_{0}$ at temperature $T_{0}$, then when $\sigma_{0}$ is removed at $t=0$ and $T$, the creep strain $\epsilon_{\mathrm{R}}$ recovers according to the relation

$$
\left.\epsilon_{R^{(i, ~}} T, \sigma_{0}\right)=\sigma_{o}\left[E_{u}(T)\right]^{-1}\left[A_{\sigma}\left(q^{*}\right)-A_{\sigma}(q)\right]
$$

where

$$
q^{*}=q_{0}+\left(10^{-3}\right) \mathrm{T} \ln [1+(t / t *)]
$$

and

$$
\ln \mathrm{t}^{*}=10^{3}\left(\mathrm{q}_{\mathrm{O}} / \mathrm{T}\right)-\mathrm{C}
$$

In this derivation the slight temperature dependence of $E_{u}$ has been neglected.

The property of creep recovery may at times be a significant consideration in the design and use of metal matrix composites. For example, for those composites formed by stressing boron fibers at high temperature, fiber recovery will be small as long as the inequality $A(q)<A\left(q^{*}\right)$ is maintained. However, any high temperature excursions during use condi- 
tions could induce dimensional changes which would be unexpected under the assumption of a plastic fiber. Alternatively, recoverability might be employed to remove by proper heat treatment any undesired composite creep developed during use. Obviously this technique requires matrices with near zero creep resistance at the treatment temperature. Along these lines it should be understood that to date complete strain recoverability has only been accurately studied under conditions of high vacuum. The possibility may exist that high temperature air and matrix environments produce enough contamination to lock some of the microstructural mechanisms in the relaxed state, thereby preventing total recovery。

Stress relaxation. - Because relaxation processes are broadly distributed in energy, boron fiber stress relaxation as a function of time, temperature, and strain is directly determinable from the anelastic strain function; $i$. $e_{\circ}$,

$$
\sigma(\mathrm{t}, \mathrm{T}, \epsilon)=\mathrm{E}_{\mathrm{u}}(\mathrm{T}) \epsilon / \mathrm{A}_{\sigma}(\mathrm{q})
$$

Damping capacity. - The damping capacity $\psi$ of a vibrating system is the ratio of the energy loss per cycle to the total stored energy. Since the $\log$ decrement $\delta=\psi / 2$, it follows from $\mathrm{Eq}$. (13) that for a boron fiber

$$
\psi(\mathrm{f}, \mathrm{T})=\frac{\pi^{2} \mathrm{~T}}{10^{3}}\left[\frac{\mathrm{dA}_{\sigma}}{\mathrm{A}_{\sigma} \mathrm{dq}}\right]_{\mathrm{t}=(2 \pi \mathrm{f})^{-1}}
$$

Figure 2, which plots the low stress $\delta(\mathrm{T})$ near $1 \mathrm{kHz}$ indicates a rapid rise in $\psi(T)$ with significantly large values $\left(\psi_{\max } \cong 24\right.$ percent) within the use-temperature range of metal matrix composites. Although high stress $\delta(\mathrm{T})$ data has yet to be taken, the low $\mathrm{q}$ slope of $\mathrm{A}_{\mathrm{H}}$ in comparison to $\mathrm{A}_{\mathrm{L}}$ suggests that high vibrational stresses should induce even larger $\psi$ 
at lower temperatures (cf. Peak Ia**[4]). Obviously this behavior should be considered in vibrating composite systems, especially since the contribution from the fiber or matrix to the composite $\psi$ is directly proportional to the component's stored energy or modulus. For example, neglecting the interface and other sources of energy loss, one can write for axial vibration that

$$
\psi_{\text {comp }}=\frac{(\mathrm{VE} \psi)_{\text {fiber }}+(\mathrm{VE} \psi)_{\text {matrix }}}{(\mathrm{VE})_{\text {fiber }}+(\mathrm{VE})_{\text {matrix }}}
$$

where $\mathrm{V}$ is the volume fraction. Thus for a 50 vol percent boron/ aluminum composite, over 80 percent of $\psi_{\text {comp }}$ is contributed by $\psi_{\text {fiber }}$. Clearly if boron fibers were assumed elastic with no damping capacity, a significant mechanical property would be neglected.

Fracture. - The temperature-dependent fracture results of this study coupled with Smith's UTS results at $22^{\circ} \mathrm{C}\left(72^{\circ} \mathrm{F}\right)[8]$ confirm the important role of the core flaw in the fracture behavior of modern boron fibers vapor-deposited on a tungsten wire substrate. The model that emerges is that of a "composite" fiber consisting of an elastic tungsten-boride core within an anelastic boron sheath. When etching removes surface flaws from commercial $203 \mu \mathrm{m}(8 \mathrm{mil})$ as-received fibers, essentially no flaws remain in the sheath of strength less than that of the core flaw. Thus fracture in these fibers is produced by the elastic extension of the core region to its fracture strain as modified by internal residual stresses (cf. appendix I). The situation is not as clear in $102 \mu \mathrm{m}(4 \mathrm{mil})$ and $143 \mu \mathrm{m}(5.6 \mathrm{mil})$ fibers where Smith has observed a larger variation in UTS after etching. This might be explained either by flaws in the boron sheath or more likely by incomplete core development due to reduced deposition times. 
Fracture of etched fibers occurs, therefore, at the nearly constant fracture strain of the tungsten boride core. Fracture stress, on the other hand, decreases with time and temperature in a manner dependent on the anelastic axial creep of the boron sheath。 Its value can be simply derived from Eq. (17) as that stress required to deform the fiber to the core fracture strain $\epsilon_{\mathrm{F}}^{\mathrm{C}}$; i.e.

$$
\sigma_{F}(t, T, d)=\frac{E_{u}(T) \epsilon_{F}^{C}(d)}{A_{H}(q)}=\left[\frac{E_{u}(T)}{E_{u}(T)}\right]\left[\frac{A_{H^{\prime}}\left(q_{O}\right)}{A_{H}(q)}\right] \sigma_{F}\left(q_{o}, d\right)
$$

Here $d$ is the diameter of the etched fiber and stress contribution of the $17 \mu \mathrm{m}$ core has been neglected. This result suggests that given a fiber with a core-initiated fracture stress $\sigma_{F}\left(q_{O}, d\right)$ at a certain $q_{O}$ value, one can now predict from $\mathrm{A}_{\mathrm{H}}$ its fracture stress at any other $q$, provided, of course, that the particular use conditions do not alter $\epsilon_{\mathrm{F}}^{\mathrm{C}}$ or initiate flaws or lower strength than the core. The practical significance is quite dramatic when one considers that all types of time-dependent stress applications are included, ranging from impact tests through tensile tests to long time stress-rupture tests. For example, if the average UTS of a group of fibers is $2.76 \mathrm{GN} / \mathrm{m}^{2}(400 \mathrm{ksi})$ at room temperature $\left(\mathrm{A}_{\mathrm{H}} \cong 1.15\right)$, their average fracture stress at $300^{\circ} \mathrm{C}\left(572^{\circ} \mathrm{F}\right)$ will be as high as $2.4 \mathrm{GN} / \mathrm{m}^{2}$ (350 ksi) for impact tests of $1 \mathrm{msec}$ duration $\left(\mathrm{A}_{\mathrm{H}} \cong 1.3\right)$, but will decrease to $1.7 \mathrm{GN} / \mathrm{m}^{2}(240 \mathrm{ksi})$ for 1000 hour stress-rupture tests $\left(A_{H} \cong 1.9\right)$. Clearly the Eq。(25) calculation can be applied directly to unidirectional composites and to axial fracture conditions in which any two of the three variables time, temperature, and stress are known.

There are two other important implications of the core fracture model that should be considered. On the negative side, boron fibers allowed to 
creep at high temperature under stress and then lowered in temperature should have a reduced UTS at room temperature. This behavior is explained by the fact that a certain tensile creep strain is quenched into the sheath and core, thereby requiring less elastic strain to achieve core fracture at the lower temperatures. On the positive side, however, it may be possible to creep boron fibers in compression at high temperature, as, for example, during composite production. This treatment should quench in a compressive strain in the core, resulting in a higher UTS at room temperature. One calculates that if a fiber were subjected to a compres sive axial stress $\sigma$ for one hour at $500^{\circ} \mathrm{C}\left(932^{\circ} \mathrm{F}\right)$ or one second at $688^{\circ} \mathrm{C}\left(1270^{\circ} \mathrm{F}\right)$, its room temperature UTS would increase by $\sim \sigma$ ?

\section{CONCLUSIONS}

Due to the analytical nature of anelastic deformation, it is now possible to predict more accurately the mechanical behavior of CVD boron fibers both as free fibers as reinforcement in a composite. At low tem perature and short times these fibers can be considered as elastic materials; but as temperature or time is increased, anelastic behavior begins to manifest itself significantly in many nondestructive and destructive mechanical properties. Our desire in this paper was not to discuss in detail the anelastic implications for a wide range of design situations. Rather, it was our belief that a brief insight into possible effects would aid the composite designer in obtaining enough understanding to more fully exploit boron fiber anelasticity for his own composite problem. 
APPENDIX I - CORE FRACTURE STRAIN

For an as-received boron fiber of diameter $\bar{d}_{0}(=203 \mu \mathrm{m})$ etched to diameter $d$, the fracture strain $\epsilon_{F}^{C}(d)$ of its tungsten boride core can be considered to consist of four components:

$$
\begin{aligned}
\epsilon_{\mathrm{F}}^{\mathrm{C}}(\mathrm{d}) & =\epsilon_{\mathrm{F}}^{\mathrm{C}}\left(\mathrm{d}_{\mathrm{o}}\right)-\epsilon_{\mathrm{z}}(\mathrm{d}, \mathrm{q}) \\
& =\left[\epsilon_{\mathrm{F}}^{\mathrm{C}}(0)-\epsilon_{\mathrm{v}}\left(\mathrm{d}_{\mathrm{o}}\right)-\epsilon_{\mathrm{x}}(\mathrm{T})\right]-\epsilon_{\mathrm{z}}(\mathrm{d}, \mathrm{q})
\end{aligned}
$$

where

$\epsilon_{\mathrm{F}}^{\mathrm{C}}(0) \quad$ fracture strain of a core free of the boron sheath (assumed to be temperature independent),

$\epsilon_{\mathrm{v}}\left(d_{\mathrm{o}}\right) \quad$ residual deposition strain produced near $1300^{\circ} \mathrm{C}$ by boriding of tungsten substrate and by vapor deposition of boron,

$\epsilon_{\mathrm{x}}(\mathrm{T}) \quad$ residual thermal strain due to difference in thermal expansion between boron sheath and tungsten boride core, $\epsilon_{\mathrm{z}}(\mathrm{d}, \mathrm{q})$ residual etching strain produced by removing outer compressive layers of the boron sheath $\left[\epsilon_{\mathrm{z}}\left(\mathrm{d}_{\mathrm{o}}, \mathrm{q}\right) \equiv 0\right]$

For the particular fibers of this study, Behrendt [12] has measured near room temperature the $\operatorname{sum}\left(\epsilon_{\mathrm{v}}+\epsilon_{\mathrm{x}}\right)$ and the etch strain $\epsilon_{\mathrm{z}}(143 \mu \mathrm{m})$ and found both to be compressive (negative). Thus the fracture strain for the core in the etched fiber is greater than that of a free core.

Regarding the effects of temperature on $\epsilon_{F}^{C}(d)$, the constancy of Smith ${ }^{i} \mathrm{~S}$ maximum UTS data at $22^{\circ} \mathrm{C}$ [8] suggests that $\epsilon_{\mathrm{F}}^{\mathrm{C}}\left(\mathrm{d}_{\mathrm{O}}\right)$ is not affected by heat treating the as-received fibers to $900^{\circ} \mathrm{C}$ for 1.5 hours. (The UTS falloff from 600 to $900^{\circ} \mathrm{C}$ was recovered completely by etching, thereby indicating the influence of thermally-induced surface defects above $600^{\circ} \mathrm{C}_{0}$ ) The insensitivity of $\epsilon_{\mathrm{F}}^{\mathrm{C}}\left(\mathrm{d}_{\mathrm{O}}\right)$ to heat treatment further suggests that up to 
at least $900^{\circ} \mathrm{C}$ there is negligible change in $\epsilon_{\mathrm{V}}\left(\mathrm{d}_{\mathrm{o}}\right)$ and the core deforms elastically (i。e., no core creep).

For $\epsilon_{\mathrm{x}}(\mathrm{T})$, the observation of similar thermal expansion coefficients near room temperature [17] coupled with the temperature dependence of their specific heats [18] suggest through Gruneisen's equation [19] that the core and sheath expand similarly up to $\sim 500^{\circ} \mathrm{C}$ where the $\mathrm{W}_{2} \mathrm{~B}_{5}$ expansion rate begins to decrease slightly. In terms of $\epsilon_{\mathrm{x}}(\mathrm{T})$, this behavior can be interpreted as a constant compressive $\epsilon_{\mathrm{x}}$ of about $10^{-3}$ until $500^{\circ} \mathrm{C}$ where $\epsilon_{\mathrm{x}}$ begins to decrease, reaching zero at the deposition temperature.

The contraction strain $\epsilon_{\mathrm{z}}(\mathrm{d}, \mathrm{q})$ is the result of elastic plus anelastic recovery of the inner tensile regions in the boron sheath [12]. Its value can be calculated from the superposition principle [5]:

$$
\epsilon_{\mathrm{z}}(\mathrm{d}, \mathrm{q})=\sigma_{\mathrm{z}}(\mathrm{d}) \mathrm{A}(\mathrm{q}) / \mathrm{E}_{\mathrm{u}}(\mathrm{T})
$$

where $\sigma_{z}(d)$ is a fictitious compressive stress produced by the removal of outer compressive layers. Those fibers tested below $\mathrm{T}=373^{\circ} \mathrm{K}$ in this study were assumed to have an $\epsilon_{\mathrm{z}}$ value determined by $\mathrm{d}=143 \mu \mathrm{m}$ and $A\left(q^{\gamma}\right)$ where $q^{\gamma}$ corresponds to the etch conditions of $\sim 10 \mathrm{~min}$. at $100^{\circ} \mathrm{C}$. Fracture of these fibers occurs, therefore, when $\epsilon_{\mathrm{D}}$ of the sheath equals $\epsilon_{\mathrm{F}}^{\mathrm{C}}(\mathrm{d})$; or, from Eq. (I1), when

$$
\frac{\sigma_{F}(\dot{q}, d) A(q)}{E_{u}(T)}=\frac{\sigma_{F}\left(0, d_{0}\right)}{E_{u}(0)}-\frac{\sigma_{z}(d) A\left(q^{p}\right)}{E_{u}(T)}
$$

Assuming from our low $q$ data that $A(q)=1.15$ for Smith's UTS versus $\mathrm{d}$ results [8], we estimate $\sigma_{\mathrm{F}}\left(0, \mathrm{~d}_{\mathrm{o}}\right)=5.17 \mathrm{GN} / \mathrm{m}^{2}(750 \mathrm{ksi})$ and $\sigma_{\mathrm{z}}(143 \mu \mathrm{m})=-0.55 \mathrm{GN} / \mathrm{m}^{2}(-80 \mathrm{ksi})$. For the high temperature fracture tests, these stress values are inserted into Eq. (I3) with appropriate 
$\epsilon_{\mathrm{X}}(\mathrm{T})$ correction and $\mathrm{A}\left(\mathrm{q}^{\circ}\right)$ replaced by $\mathrm{A}(\mathrm{q})$ to account for the additional contraction produced by $\sigma_{\mathrm{z}}$ for $\mathrm{T}>373^{\circ} \mathrm{K}$ 。 The resulting equation is then employed with the experimental $\sigma_{F}(q, d)$ to determine $A(q)$. Although the corrections for the thermal dependence of $\epsilon_{\mathrm{x}}$ and $\epsilon_{\mathrm{z}}$ are somewhat compensating and affect $A$ only slightly, the actual occurrence of the $\sigma_{z}$ effect appears to be supported by Smith's observation of higher room temperature UTS for etched fibers heat treated near $500^{\circ} \mathrm{C}$. Obviously the correction for this effect could be eliminated by prior heat treatment above the fracture test temperatures. 


\section{APPENDIX II - BORON FIBER THERMAL EXPANSION}

Employing published data on thermal expansion over large temperature intervals, we have calculated the boron fiber thermal expansion coefficient $\alpha(\mathrm{T})$ through the Gruneis en equation [19]:

$$
\left[\frac{\mathrm{C}_{\mathrm{v}}}{3 \alpha}\right]^{1 / 2}=\left[\frac{\mathrm{C}_{\mathrm{v}}}{3 \alpha}\right]_{\mathrm{H}=0}^{1 / 2}-\mathrm{bH}
$$

Here $C_{\mathrm{V}}$ is the specific heat at constant volume $\left(\mathrm{cal} / \mathrm{mole} /{ }^{\circ} \mathrm{C}\right), \mathrm{H}$ is the internal energy (cal/mole), and $b$ is a constant equal to $\sim 0.01$ (mole/ cal $)^{1 / 2}$. Because the Debye temperature $\theta$ of amorphous boron is $\sim 1200^{\circ} \mathrm{K}$, the approximation $\mathrm{C}_{\mathrm{v}}=\mathrm{C}_{\mathrm{p}}$ is fairly accurate for $\mathrm{T}<\theta$. With the amorphous $\mathrm{C}_{\mathrm{p}}(\mathrm{T})$ and $\mathrm{H}(\mathrm{T})$ results of Wise et al. [20], we have adjusted $\alpha(\mathrm{T})$ in the Gruneisen equation to fit the following boron fiber data:

$$
\begin{aligned}
& \bar{\alpha}=4.9 \times 10^{-6} \text { per }^{\circ} \mathrm{C}, 300-600^{\circ} \mathrm{K}[21] \\
& \bar{\alpha}=5.4 \times 10^{-6} \text { per }^{\circ} \mathrm{C}, 300-600^{\circ} \mathrm{K} \cdot[17] \\
& \bar{\alpha}=8.5 \times 10^{-6} \text { per }^{\circ} \mathrm{C}, 300-1300^{\circ} \mathrm{K}[17] \\
& \bar{\alpha}=8.3 \times 10^{-6} \text { per }^{\circ} \mathrm{C}, 300-1300^{\circ} \mathrm{K}[22]
\end{aligned}
$$

Our results for $\alpha$ and the parameter $\lambda=\int_{0}^{\mathrm{T}} \alpha \mathrm{dT}$ are shown as a function of $\mathrm{T}$ in $\mathrm{Fig} .8$. 
REFERENCES

1. Breinan, E。 M. and Kreider, K。 G。, Metallurgical Transactions, Vol. 1, 1970, pp.93-104.

2. Metcalfe, A。G。and Schmitz, G。K., Journal of Engineering for Power, Vol.91, 1969, pp.297-303.

3. Prewo, K。 M。, Journal of Composite Materials, Vol. 8, 1974, pp. 411-414。

4. DiCarlo, J。 A。, Scripta Metallurgica, Vol。10, 1976, pp. 115-119.

5. Nowick, A。S。 and Berry, B。S., Anelastic Relaxation in Crystalline Solids, Academic Press, New York, 1972.

6. DiCarlo, J。A., Snead, C。 L。, and Goland, A. N., Physical Review, Vol。178, 1969, pp。1059-1072。

7. Nowick, A。S。 and Berry, B。S。, IBM Journal of Research and Development, Vol。5, 1961, pp。297-311.

8. Smith, R。 J。, NASA TN D-8219, National Aeronautics and Space Administration, Cleveland, Ohio, 1976.

9. Rose, F。K。 and Stokes, J. L。, "Advanced Methods to Test Thin Gage Materials, "Technical Report AFML-TR-68-64 Air Force Materials Laboratory, Dayton, Ohio, 1968.

10.Veltri, R。 and Galasso, F。, Nature, Vol。220, 1968, pp.781-782.

11. Ericksen, R。Ho, Metallurgical Transactions, Vol.4, 1973, pp.16871693 。

12. Behrendt, D。 R。, Composite Materials: Testing and Design (Fourth

Conference), Am. Soc. for Testing and Materials, Philadelphia, 1976.

13. Firle, T. E., Journal of Applied Physics, Vol. 39, 1968, pp. 2839-2845. 
14. Lindquist, $P . F_{\circ}$, Hammond, $M_{\circ} L_{\circ}$, and Bragg, R。 $H_{\circ}$, Journal of Applied Physics, Vol.39, 1968, pp.5152-5162.

15. Cook, J。 L。, and Sakurai, T. T., Advanced Fibrous Reinforced Composites, Vol.10, Soc. of Aerospace Material and Process Engrs., 1966, pp. H1 to H11.

16. Ellison, E. G。 and Boone, D. H., Journal of Less Common Metals, Vol。13, 1967, pp. 103-111.

17. Witucki, R。 M. "High Modulus, High Strength Filaments and Composites, "Technical Report, AFML-TR-66-187, Air Force Materials Laboratory, Dayton, Ohio, 1967.

18. Touloukian, Y. S., ed., Thermophysical Properties of High Temperature Solid Materials, Vol. 1, Macmillan Co., New York, 1967, p. 71. Touloukian, Y. S., ed., Thermophysical Properties of High Temperature Solid Materials, Vol.6, Pt. 1, Macmillan Co., New York, 1967, p. 256.

19. Zemansky, M。W。, Heat and Thermodynamics, McGraw-Hill, New York, 1957, pp.272-275.

20. Wise, S. S。, Margrave, J. L。, and Altman, R. L., Journal of Physical Chemistry, Vol。64, 1960, pp.915-917.

21. Lasday, A. H., and Talley, C. P., Advanced Fibrous Reinforced Composites, Vol, 10, Soc. of Aerospace Material and Process Engrs。, 1966, pp。D-1 to D-24.

22. Shaffer, P. T. B., Handbook of High Temperature Materials, No. 1, Plenum Press, New York, 1964, p. 191. 


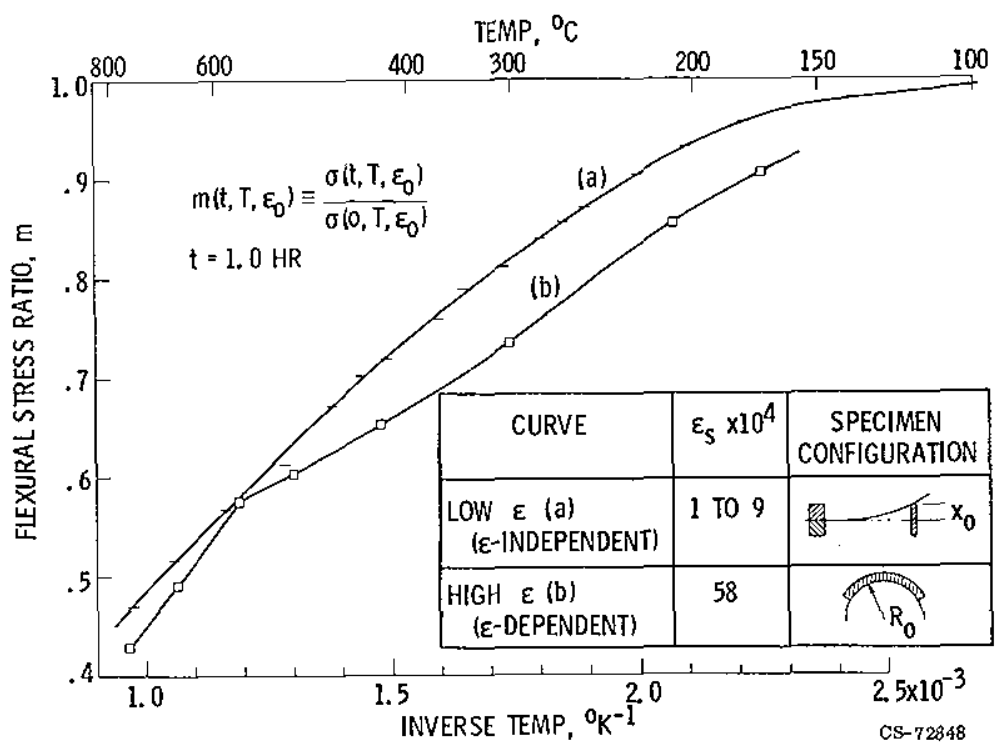

Figure 1. - One hour flexural stress relaxation (FSR) of $203 \mu \mathrm{m} 18 \mathrm{mili}$ boron fibers as a function of temperature and average surface strain $\varepsilon_{\mathrm{s}}$.

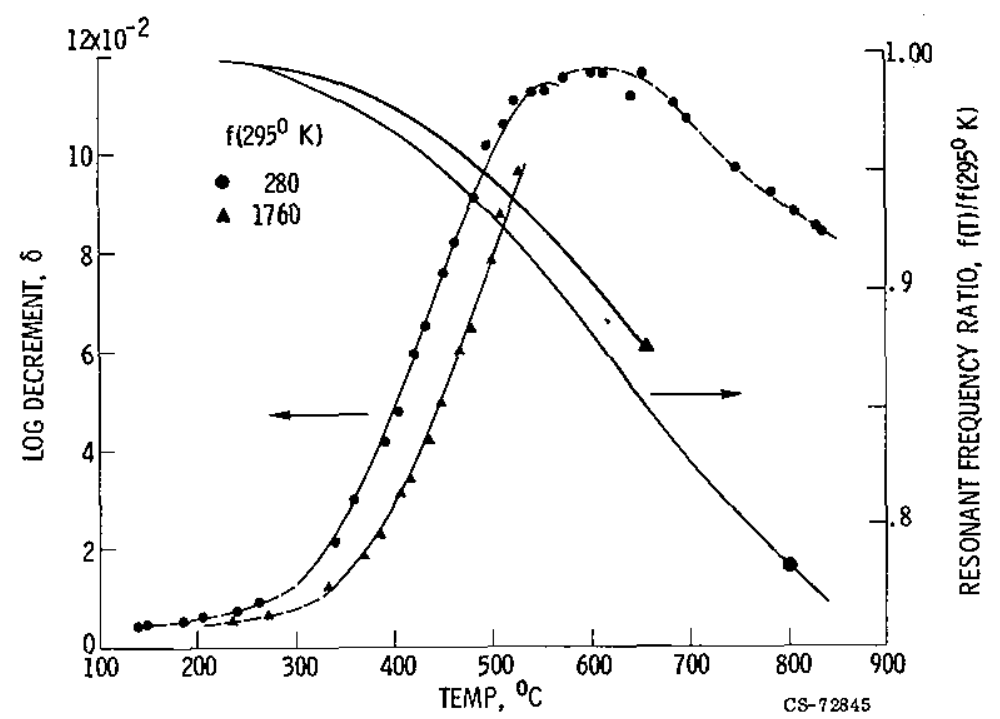

Figure 2. - Flexural internal friction (FIF) and vibration frequency at two resonant modes of a cantilevered boron fiber. 


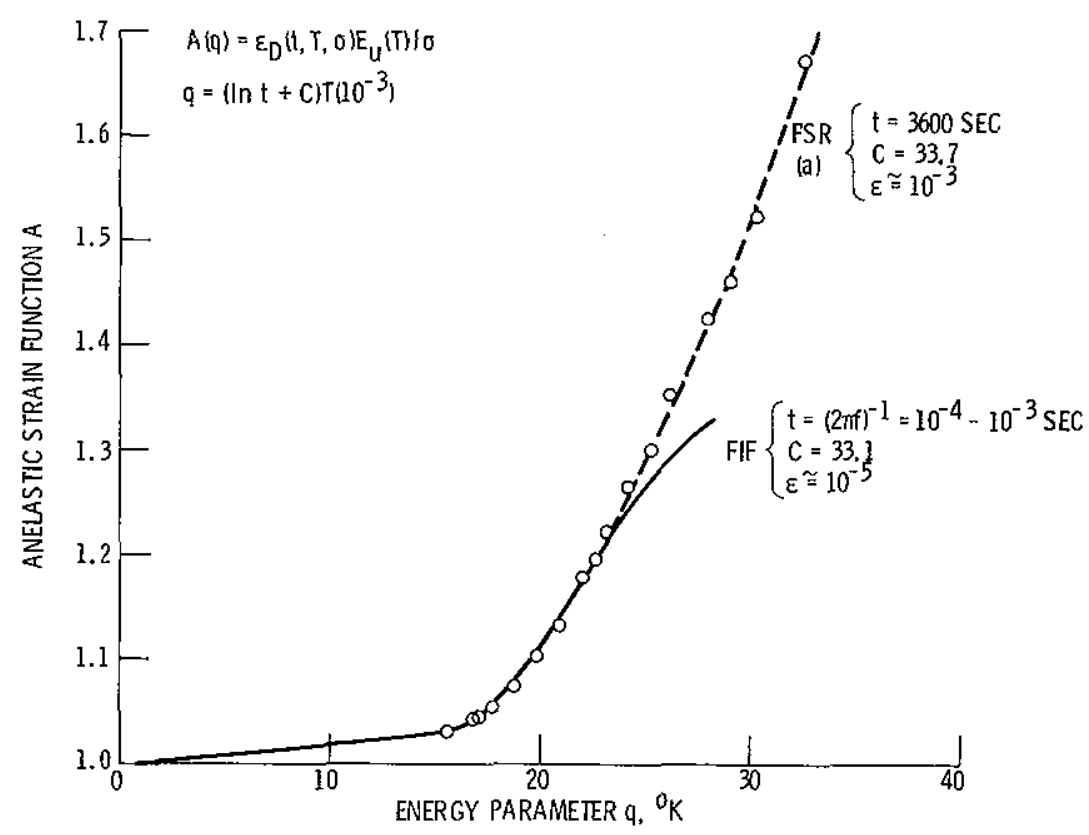

Figure 3. - Anelastic strain function for boron fibers as derived from low strain flexural deformation data. Time (sec) and temperature ( $\mathrm{NK}$ ) are both contained in the single energy parameter q.

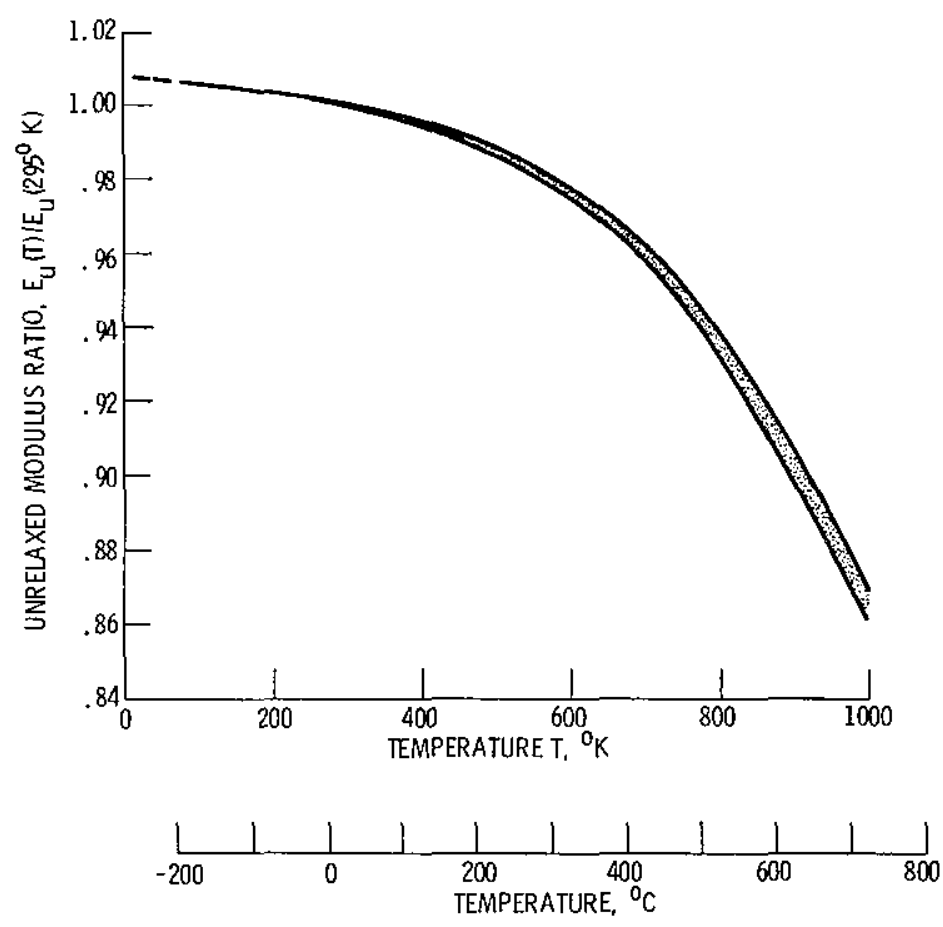

Figure 4. - The temperature dependence of the unrelaxed Young's modulus of boron fibers as derived from resonant frequency data and anelastic theory. 

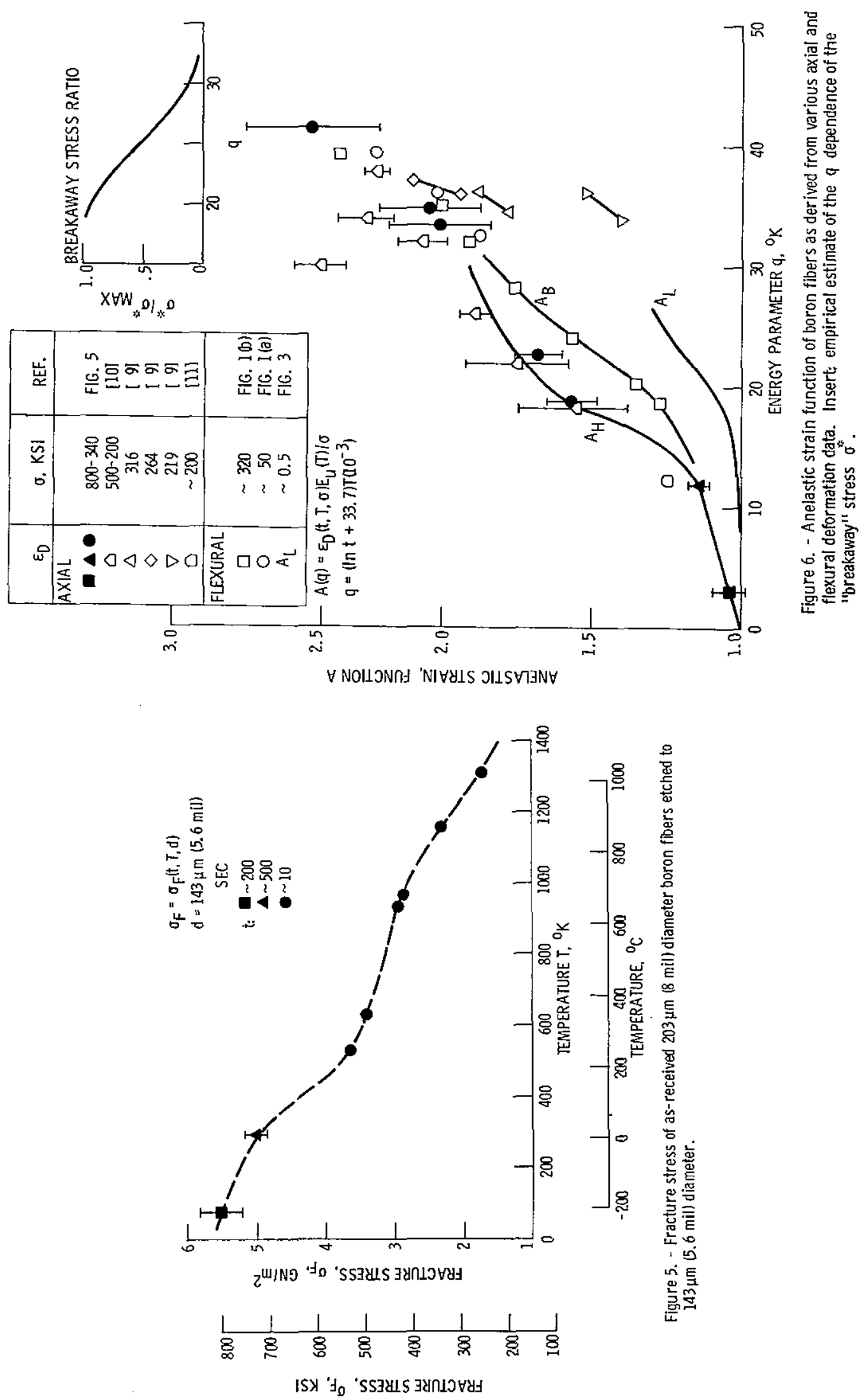

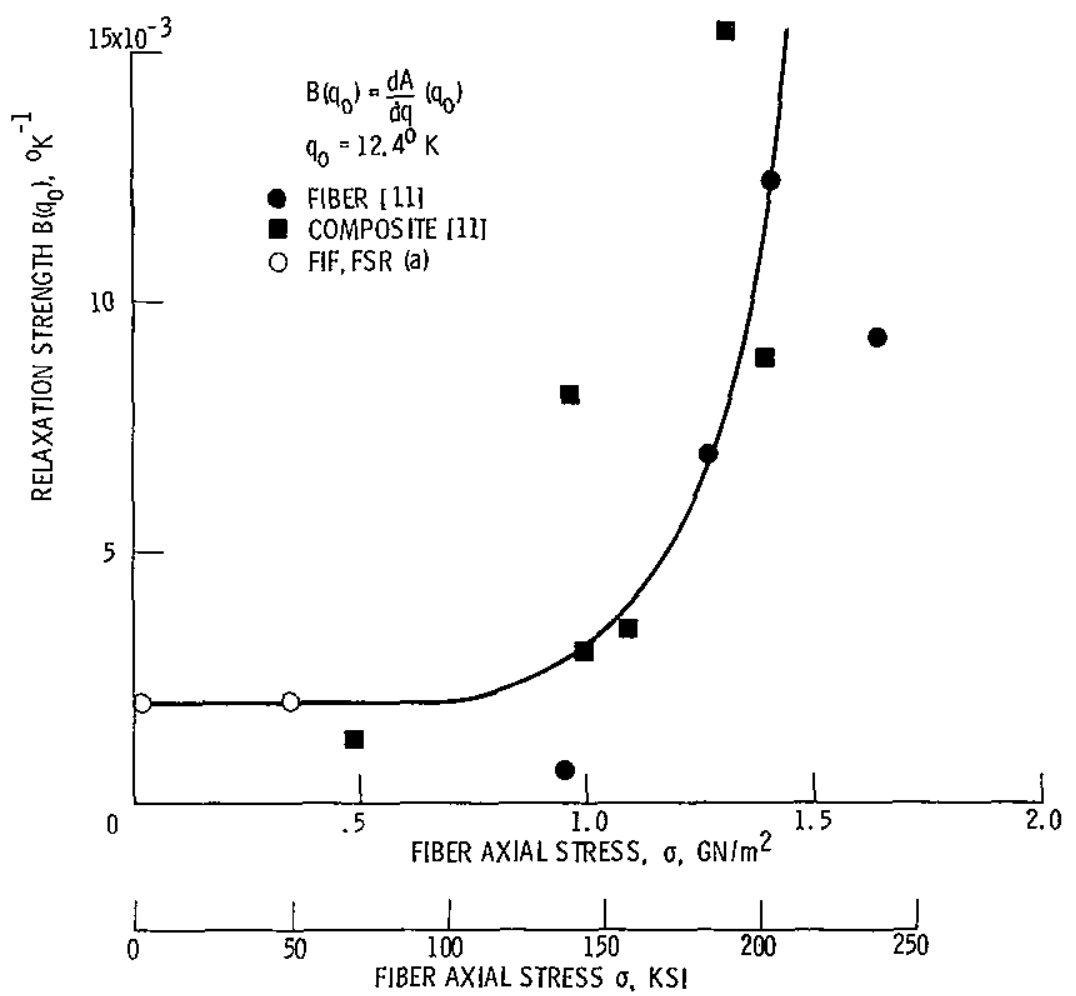

Figure 7. - Stress dependence of $B\left(q_{0}\right)$, the relaxation strength or number of anelastic processes with energy $q_{0}$.

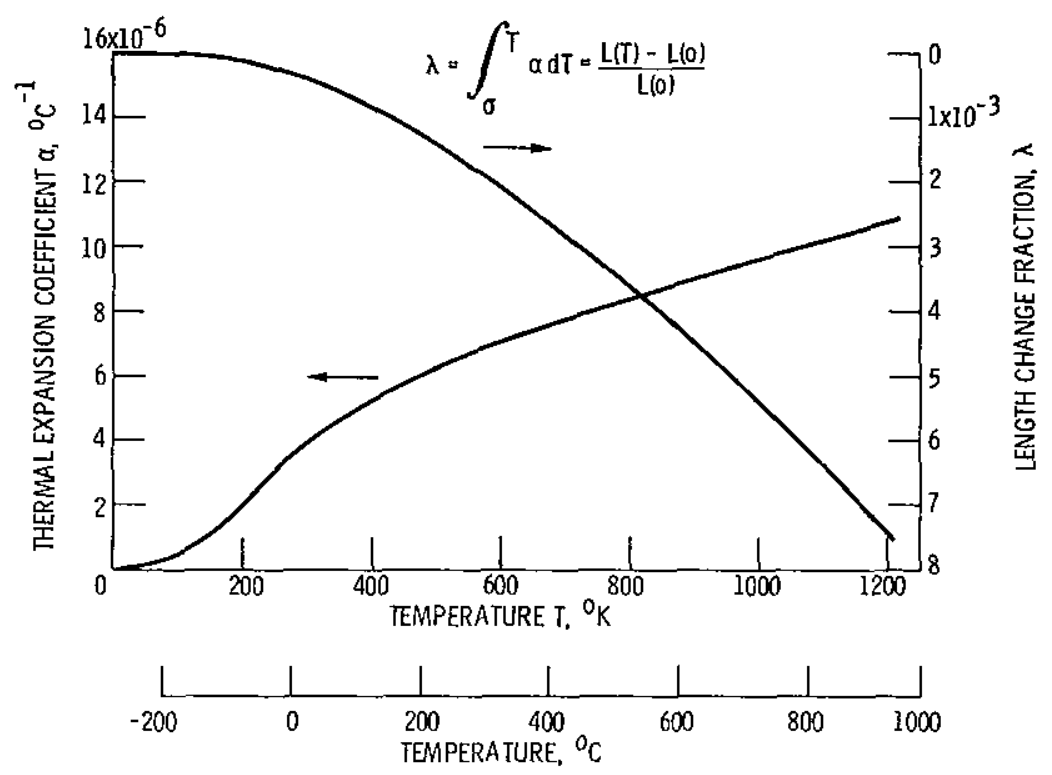

Figure 8. - Thermal expansion parameters of boron fibers as derived from Gruneisen's equation and expansion data. 